\title{
QUALIDADE DE VIDA DE PROFESSORES DO ENSINO SUPERIOR NA ÁREA DA SAÚDE: DISCURSO E PRÁTICA COTIDIANA
}

\author{
Átala Lotti Garcia ${ }^{1}$, Elizabete Regina Araújo Oliveira² ${ }^{2}$ Elizabete Barros de Barros ${ }^{3}$
}

RESUMO: Estudo sobre qualidade de vida de professores do ensino superior no contexto da reestruturação produtiva, tomando-se como eixo de análise as variáveis que interferem na qualidade de vida. O objetivo foi analisar as condições de trabalho dos professores de ensino superior na área da saúde no âmbito das transformações econômicas, sociais e culturais vividas no contemporâneo. Foi utilizada uma metodologia qualitativa que apresenta as avaliações desses trabalhadores sobre as condições/ organização do trabalho docente e suas repercussões na qualidade de vida e saúde dos professores. Os resultados apresentam relatos sobre o sofrimento com a situação em que se encontra o professor atualmente, marcado pela desvalorização do seu trabalho, acirrada competitividade do mercado que afeta sua saúde. As conclusões apontam em direção à urgência de se pensar e discutir amplamente essa situação vivida nas instituições de Ensino Superior, uma vez que os processos de trabalho têm importância capital na produção de saúde-doença.

PALAVRAS-CHAVE: Saúde do trabalhador; Professores na área da saúde; Qualidade de vida.

\section{QUALITY OF LIFE OF SUPERIOR EDUCATION TEACHERS IN THE HEALTH AREA: SPEECH AND DAILY PRACTICE}

\begin{abstract}
Study on the quality of life of Superior Education teachers in the context of the productive reorganization, taking the variables that interfere in the quality of life as the analysis axis. It objectified to analyze superior educational teachers' working conditions from the health area in the scope of contemporaneous economic, social and cultural transformations. A qualitative methodology was used, presenting those professionals' assessments on working conditions/ organization as well the repercussions in their quality of life and health. The results present accounts on the suffering with their current situation, marked by work depreciation, fierce market competition which affect their health. The conclusions point out the urgent need to think over and broadly discuss this situation lived in the institutions of Superior Education as work processes further health-illness development.
\end{abstract}

KEYWORDS: Professionals' Health; Teachers in the health area; Quality of life.

\section{CUALIDAD DE VIDA DE LOS PROFESORES DE LA ENSEÑANZA SUPERIOR EN EL AREA DE LA SALUD: DISCURSO Y PRÁCTICA COTIDIANA}

RESUMEN: Este estudio presenta un análisis sobre la cualidad de vida de los profesores del curso superior en el contexto de la restructuración productiva. Se toman como eje de analisis las variables que interfieren en la cualidad de vida. El objetivo fue analizar las condiciones de trabajo de los profesores del curso superior en el área de la salud en ambito de las transformaciones económicas, sociales y culturales vividas en el mundo contemporaneo. Fue utilizado un método de cualidad que presenta las evaluaciones de estos trabajadores acerca de la organización del trabajo docente y sus repercuciones en la cualidad de la vida y salud de los profesores. Los resultados presentan relatos acerca de las dificultades con la situación en que se encuentra el profesor actualmente, marcado por la desvalorización de su trabajo, gran competitividad del mercado, entre otras cosas, lãs cuales afectan su salud. Las conclusiones apuntan en dirección a la urgência de pensar y discutir aplamente esta situación vivida en las instituciones del curso superior, una vez que los procesos de trabajo tienen la importancia principal en la salud y en la enfermidad.

PALABRAS CLAVES: Salud del trabajador; Profesores em área de la salud; Cualidad de vida.

\footnotetext{
${ }^{1}$ Terapeuta Ocupacional. Mestre em Atenção à Saúde Coletiva pelo PPGASC/Universidade Federal do Espírito Santo-UFES. Docente do curso de Terapia Ocupacional da FAESA.

${ }^{2}$ Doutora. Docente do Programa de Pós graduação em Atenção à Saúde Coletiva e do Curso de Graduação em Enfermagem da UFES. ${ }^{3}$ Doutora em Psicologia. Docente do Departamento de Pós graduação em Psicologia e Educação e do Curso de Graduação em Psicologia da UFES.
}

Autor correspondente:

Átala Lotti Garcia

Rua Paru, 784 - Belo Horizonte - MG

E-mail: atalagarcia@hotmail.com

Recebido: 11/06/07

Aprovado: 07/04/08

Cogitare Enferm 2008 Jan/Mar; 13(1):18-24 


\section{INTRODUÇÃO}

A problemática das articulações entre as atuais transformações do trabalho docente e a saúde do conjunto de trabalhadores das Instituições de Ensino Superior em suas múltiplas dimensões é tomada neste trabalho como aspecto prioritário de análise e, por se tratar de fatores que interferem na qualidade de vida, destacamos o trabalho como um fator importante.

Os últimos anos, décadas entre 1980 e 2000, foram marcados por mudanças na economia, na organização produtiva brasileira e na organização do trabalho, permitindo manter e/ou aumentar os níveis de produção com um número cada vez menor de trabalhadores. O setor da educação superior, com destaque, a área da saúde, sofre os efeitos de políticas públicas atuais que incentivam a competição, a desregulamentação da economia, a proposição do Estado mínimo com a redução dos investimentos nas áreas de saúde, educação e moradia.

Essas mudanças ocasionaram transformações no mercado de trabalho, que passou a necessitar de mão-de-obra cada vez mais especializada para atender as demandas dessa política hegemônica que se expressa, dentre outros aspectos, na exigência de constante 'aperfeiçoamento técnico'. Junto com o aumento das exigências por qualidade manteve-se em crescimento a já conhecida demanda por produtividade, traduzida num 'produtivismo', cuja preocupação fundamental não se refere à qualidade de vida dos humanos, o que acarreta em aumento do receio pelo trabalhador de demissão da instituição( ${ }^{(1)}$.

Em relação aos docentes, estes passaram a submeter-se a longas jornadas de um trabalho, que requer o componente cognitivo intenso e complexo, com uso de códigos múltiplos e diversificação de atividades, necessitando de rápidas tomadas de decisões.

O tipo de reflexão proposta aponta para o entendimento do modelo de sociedade em curso e os modos de produção. A sociedade atual é marcada pela presença hegemônica do capital e cuja relação com o trabalho está na base da definição das classes sociais e define as próprias condições de produção e reprodução da força de trabalho. Portanto, para abrir perspectivas de compreensão do trabalho docente e sua relação com a saúde, faz-se necessária uma análise que revele a complexidade da dinâmica dessas relações e não apenas a verificação mecânica dos impactos do trabalho sobre as/os professoras/es ${ }^{(2: 8)}$.

Agregado aos aspectos mencionados anteriormente, a maioria dos professores da saúde são mulheres que acumulam algumas vezes até três jornadas de trabalho: na saúde, na educação e no domicílio. Esse acúmulo de atividades e responsabilidades assumidas repercute na saúde desses trabalhadores podendo contribuir na produção de níveis variados de estresse, a doença de Burnout, entre outros problemas psicossomáticos ${ }^{(3)}$.

A doença de Burnout, representa uma resposta ao estresse ocupacional crônico gerado pelas características do ambiente laboral e pela discrepância entre as expectativas do indivíduo e a realidade enfrentada no seu trabalho e afeta especialmente trabalhadores com intenso contato com pessoas, como nos setores de Educação e Saúde. Corroboram com essas digressões, investigações realizadas sobre a saúde mental dos professores do ensino fundamental e ensino médio em todo Brasil que revelaram que $26 \%$ da amostra estudada apresentavam exaustão emocional. A desvalorização profissional, "baixa autoestima" e ausência de resultados positivos percebidos no trabalho desenvolvido foram fatores importantes para o quadro encontrado ${ }^{(4)}$.

Buscando ampliar os debates sobre essa temática, iniciamos trocas com pesquisadores do campo da saúde do trabalhador, no sentido de alimentar as discussões nessa área e contribuir com a formulação teórica, conceitual e metodológica em saúde e trabalho, confrontando dados encontrados e observações sobre a situação de trabalho dos docentes, na perspectiva de sua transformação ${ }^{(5)}$.

Em face das considerações anteriores, buscamos nesse trabalho entender o discurso e prática do professor do ensino superior com enfoque na qualidade de vida.

\section{METODOLOGIA}

$\mathrm{Na}$ pesquisa adotamos uma metodologia qualitativa do tipo descritiva e exploratória a respeito da opinião dos professores de ensino superior na área da Saúde: Educação Física, Enfermagem, Fonoaudiologia, Medicina, Nutrição, Odontologia, Psicologia, Terapia Ocupacional sobre sua qualidade de vida. A importância de ouvir o discurso de cada um foi um critério importante, na medida em que compreendemos que entender o trabalho é entendê-lo a partir da forma como é experimentado por cada trabalhador, de como o constroem coletivamente e, portanto, não é possível qualquer generalização quando 
abordamos a temática da atividade de trabalho.

O estudo foi realizado com 25 docentes (19 mulheres e 6 homens) que pertenciam a Instituições de Ensino Superior (IES) na área da saúde no Estado do Espírito Santo (ES) que tinham pelo menos quatro cursos de graduação na área da saúde e da assistência, que estivessem com pelo menos $50 \%$ de seu curso em andamento.

Os dados foram coletados mediante entrevistas com os professores que se disponibilizaram em participar do estudo, as quais duraram de 15 minutos a 1 hora e vinte minutos e foram gravadas, transcritas e agrupadas por temas previamente estabelecidos. Buscamos mediante informações que expressassem as idéias, crenças, maneiras de pensar; opiniões, sentimentos, maneiras de atuar; conduta ou comportamento presente ou futuro desses trabalhadores ${ }^{(6)}$. Os professores foram entrevistados com a seguinte questão "Como você considera que esteja sua qualidade de vida em termos de dedicação à família, ao trabalho doméstico, trabalho fora de casa e lazer? Relacionando todos estes aspectos com a vida profissional", comente. Os participantes assinaram o Termo de Consentimento Livre e Esclarecido, atendendo às normas da Resolução 196/ 96, que trata de pesquisa envolvendo seres humanos. O projeto foi aprovado pelo Comitê de Ética da Universidade Federal do Espírito Santo (UFES), protocolo número 023068722839/05-38/2005.

A partir dos relatos dos sujeitos agrupados em duas categorias e estes em sub-unidades nos permite refletir sobre o que traduz o tema desta pesquisa assim, a análise das informações resultou de um material rico em experiências com dados da história de vida desses atores/autores. Buscamos dividir as falas dos participantes em duas categorias utilizando modalidade temática de análise de conteúdo proposta por Bardin ${ }^{(7)}$ em relação aos fatores que interferem na qualidade de vida dos professores: a) repercussão do trabalho nas demais relações sociais e b) condições / organização do trabalho.

\section{RESULTADOS E DISCUSSÃO}

Nos relatos que apresentamos a seguir constam fatores relativos aos aspectos sócio-demográficos da inserção na organização do trabalho e fatores que contribuem e prejudicam as condições de saúde, que podem ter implicações no processo saúde/doença e qualidade de vida.

\section{Fatores que interferem na qualidade de vida dos professores}

\section{Repercussão do trabalho nas demais relaçães sociais}

Em relação aos fatores que podem repercutir positivamente na qualidade de vida dos professores, observamos, por meio das suas falas, que a satisfação dos docentes está relacionada à produção de conhecimento sistematizado, tanto para o docente quanto para o aluno, além do impacto social que suas atividades promovem.

Considero que uma das vantagens de ser professor é o aluno entrar e sair com outro repertório [...].

Não se vê o produto final, mas o trabalho tanto na educação quanto na assistência tem uma efetiva relevância social.

A profissão de docência superior pode ser uma atividade altamente enriquecedora que proporciona ao profissional diversas habilidades ligadas ao campo da saúde. A forma e a quantidade de como se processa é que vai levá-la a ser propiciadora ou não da qualidade de vida desses atores.

Sou muito otimista, minha qualidade de vida começa por aí, consigo trabalhar em situações precárias improvisando sempre que posso. Para mim a improvisação é uma solução, você poder fazer de um problema uma solução, isto te dá qualidade de vida. Quando não se tem criatividade, a coisa deixa de ser feita, improviso na vida como improviso ao dar aulas, mas sabendo o que estou fazendo, a experiência nos dá essa mobilidade.

Por outro lado, o lazer e demais atividades sociais de modo geral parecem ser prejudicadas, principalmente as relacionadas à atividade física. Um aspecto que deve ser destacado é de que a maioria dos professores afirma que há um prejuízo no que se refere à prática de atividades físicas em função da docência. Para os sujeitos deste estudo as queixas relativas a doenças relacionadas ao sistema digestivo, respiratório, circulatório e até doenças neurológicas com sintomas como: ansiedade, tensão, insônia, dor e outras estão intensamente relacionadas às condições desfavoráveis a que os professores estão submetidos. 
Faço atividade física de uma forma muito assistemática, durante 3(três) meses ao ano [...] tento fazer mais, mas [...].

Tenho que viver de dieta, com todos os problemas que fui acometida pelo sedentarismo e estresse de base. Além de gastar mais com uma comida mais light, tenho que tomar remédio, porque não consigo fazer atividade física.

Tive uma menopausa precoce, não consigo emagrecer, e uma coisa puxa a outra.

A maioria dos professores relatam que não conseguem "desconectar" nem nas férias, referindo a necessidade de se esvaziarem, mas não conseguem o que acaba prejudicando suas atividades de lazer, culturais e esportivas. As atividades criativas espontâneas são relegadas a último plano pela maioria dos professores, como se estas tivessem pouca ou nenhuma importância.

Aonde vamos sempre carregamos material de trabalho [...].

Da vez que tirei férias, quando retornei me vi louca com o acúmulo de serviço, e não consegui ir a congressos importantes na época [...].

Estamos o tempo todo conectados com as atividades de serviço [...].

Estamos ligadas, preocupadas, as sobrecargas são grandes, de cumprimento de demandas sem fim [...].

A dedicação exagerada à atividade docente dificulta sua integração na vida para além dos espaços da faculdade. O docente se encontra sozinho sem os apoios sociais necessários, com pouco apoio institucional e mergulhado em um universo de demandas e exigências, intensificando um sentido negativo do processo de trabalho ${ }^{(8)}$.

O trabalho do docente universitário é tido como uma atividade em que este profissional possui certa autonomia para gerenciar a sua forma de organização. Entretanto, os procedimentos adotados para efetivá-lo desconsideram as questões da subjetividade dos docentes, individual e/ou coletivamente, podendo assim desencadear sofrimento no trabalho ${ }^{(9: 29)}$.

Se por um lado o professor se satisfaz com o trabalho docente, por outro, ele acaba restringindo suas atividades a vida profissional, esquecendo-se muitas vezes da importância do lazer e do contato com situações novas, sem diversificar os campos de interesse, não conseguindo dosar o trabalho e o não trabalho. $\mathrm{O}$ trabalho passa a ser a única fonte de "prazer" e outras formas acabam por ficarem no esquecimento, como por exemplo, o interesse pela arte, pela cultura e pelo esporte que parece não fazer parte das suas atividades.

De um semestre para outro mudam as pessoas [...].

Todos os meus amigos estão no mesmo esquema, então não tenho vida social [...].

Não é uma vida saudável, qualquer solicitação social a mais é um sofrimento maior [...].

A falta de "estabilidade emocional" foi outra queixa comum dos professores, tanto em relação às relações afetivas quanto das relações com as atividades do cotidiano. Dificilmente existe possibilidade de encontros com as mesmas pessoas e quando se começa a criar um vínculo, ele se desfaz, no semestre seguinte. Muitos pensam em dar continuidade a estes vínculos fora do horário de trabalho, mas a maioria não consegue tempo para encontrar com amigos, e acabam restringindo seu círculo de amizades aos familiares e vizinhos.

A interferência no relacionamento pessoal/ familiar foi outro efeito citado como correlacionado ao trabalho do professor, seguido por dificuldade de planejamento da vida. Em decorrência da carga excessiva de "atividade cognitiva" e o estresse conseqüente da corrida pela sobrevivência ocorrem alterações no sono, distúrbios gastrointestinais, cardiovasculares e desordens psíquicas.

É uma sensação de chegar no fim do dia sugado, não satisfazemos as necessidades básicas de alimentação, repouso e sexo.

Não temos rotina, isso dificulta muito [...].

Nunca sei o que será do próximo semestre [...].

Claro que temos depressão e com as doenças fisicas decorrentes e associadas.

As questões relatadas anteriormente podem 
significar uma falta de disponibilidade para a vida afetiva, para as fantasias e para o lazer significativo, o que interfere na vida social, os fluxos afetivos e a possibilidade de fantasiar, o que compromete a saúde mental dos trabalhadores ${ }^{(10)}$. As sensações, emoções, imagens ligadas ao afetivo podem dar novas formas ao mundo, dizer a respeito dos temores, dos desejos das fantasias que é singular de cada indivíduo. O espaço da intimidade é conhecido apenas por si próprio, as vezes sendo dividido por pessoas de muita confiança, o que dá um sentido de proteção, o vínculo faz o indivíduo se sentir mais seguro, o que faz com que as pessoas procurem na maioria das vezes o contato com o conhecido, familiar.

O vínculo propicia um ambiente favorável para enfrentar as muitas adversidades, para suportar níveis de angústia e falta de sentido. $\mathrm{O}$ vínculo é um dos elementos básicos do processo de aproximação e interesse pela vida social. O trabalho pode acabar atingindo e modificando as relações familiares, os amigos, as atividades criativas, o lazer e o cotidiano. Isso quando são possíveis de serem realizados, porque muitas vezes só sobra tempo para o trabalho e a família, sendo esta última, muitas vezes, mais uma demanda de atenção.

Observa-se que no mundo do trabalho, as inúmeras alterações que vêem sendo exigidas com a utilização das novas tecnologias, acabam também por interferir no ritmo e capacidade de assimilação dos trabalhadores afetando sua qualidade de vida.

\section{Condições e organização do trabalho}

As questões relativas ao financeiro, tanto do professor quanto da instituição, é mais um aspecto a ser considerado como gerador de estresse e prejuízo da qualidade de vida. Em seus depoimentos sobre as relações com o trabalho os professores destacaram a situação financeira da instituição, sua estrutura física, as pressões psicológicas e a falta de espaços de troca sobre a situação enfrentada.

Temos que ter uma empregada, o salário da empregada sobe e o seu não [...].

No topo da carreira, já estamos mais velhas, gastando mais com saúde [...]. Sem perspectiva na aposentadoria, pois o aumento não caminha com o pessoal da ativa.

[...] fazemos turismo acadêmico no máximo [...].
Os fatores objetivos como falta de equipamento e excesso de atividades extra-classe apresentam-se como prejudiciais à saúde dos professores, conforme depoimentos que se seguem.

Falta de infra-estrutura, ambiente físico insalubre [...].

Não tem um lugar para atender alunos [...].

Dificuldade em conseguir equipamentos de informática, que facilita para dar aula e, quando se consegue não tem manutenção [...].

A cobrança por uma produção que não valoriza a qualidade do trabalho, mas a quantidade, é outro fator que gera angústia e estresse, o que os faz sentir ameaçados e inseguros com a possibilidade de não estar atendendo às expectativas do mercado, que exige cada vez mais qualificação e aumenta a competição. A reflexão que se faz sobre as angústias de quem convive com os dramas do capitalismo contemporâneo é de que se por um lado ele necessita do envolvimento, da participação, da inteligência do trabalhador para fazer frente à concorrência, ao mesmo tempo, coloca em perigo os processos que podem descaracterizá-lo. As mudanças que têm ocorrido no mundo do trabalho têm a característica de subjugar todos os setores e atividades. Tanto o setor público quanto o privado passam a ser objeto dos processos modernizantes exigidos. Privatizações, enxugamento dos quadros, terceirização, programas de qualidade, são realidades hoje presentes no cotidiano das instituições de educação e saúde, além de ser invadidos pelos novos conceitos e práticas de organização muitas vezes verticalizadas $^{(11)}$.

Dão-nos condições de trabalho de terceiro e quarto mundo e uma cobrança de primeiro mundo [...].

Temos que correr atrás de publicações [...].

Estas falas corroboram com o resultado do trabalho de Martins ${ }^{(9)}$, com relação às questões do desgaste dos professores. O maior índice foi determinado pela questão "Sinto-me sobrecarregada no meu trabalho", o que nos leva a concluir que além da falta de condição de trabalho, também há uma demanda por atividades muito diversificadas dentro da academia. Os professores devem dar conta das necessidades de 
formação do aluno e da sua própria formação.

Tanto na escola pública quanto na particular percebe-se um sentimento de desvalorização da mão de obra docente, que por um lado, é cada vez mais especializada e, por outro, recebe salários cada vez menores. A este quadro, como já assinalamos, se soma as cobranças por produção e qualificação, que aumentaram consideravelmente.

\section{Existe a desvalorização financeira [...]..}

É muito cansativo [...]. É desgastante, desanima, não temos incentivo [...].

O trabalho docente, submetido a um modelo de organização que muitas vezes é teoricamente voltado para os princípios chamados humanitários, vive situações que descaracterizam o processo educativo, entendido como fator importante na produção de modos de vida potentes. São, muitas vezes, reduzidos à competição exacerbada, ao produtivismo e da fidelidade aos interesses do mercado.

\begin{abstract}
O trabalho docente cada vez mais mergulhado em burocracia, técnicas desassociadas do seu contexto sociopolítico, exigências de titulação academicista, que não interrogam os processos de formação engendrados, acabam por dificultar a análise dos processos que são atualizados no cotidiano escolar [...] o tempo de trabalho está sendo regulado em horas/aula, o ritmo é acelerado, as turmas estão superlotadas de alunos, a redução do número de profissionais sobrecarrega os que, em virtude disso, acumulam não funções, mas afazeres ${ }^{(12: 1)}$.
\end{abstract}

A modernização das relações de trabalho e de mercado visa à inserção na globalização, apesar das estruturas e processos no país permanecerem em descompasso com o contemporâneo ${ }^{(13)}$. A falta de visibilidade dos aspectos que envolvem a organização do trabalho tem resultado em uma série de conseqüências para a saúde mental dos trabalhadores. As instituições não têm tratado a organização do trabalho como um processo dinâmico, que envolve a subjetividade dos trabalhadores se preocupando mais com a segurança do corpo, com a saúde física, que no caso dos professores, fica invisível por não lidar com situações de acidente de trabalho. A psicodinâmica do trabalho procura uma análise dos processos psíquicos que mobilizam o embate entre sujeito e a realidade laborativa. Entendendo a conexão entre homem e trabalho como recurso de produção de significações internas e de construção de relações sociais, em que se faz a intervenção entre as relações internas e externas, entre o individual e o coletivo ${ }^{(14)}$.

Exigência de atualização, livros, congressos, Internet, as coisas estão muito sofisticadas com prazo de vencimento muito curto.

De acordo com o contrato formal de trabalho, temos que ministrar 8 horas aula e fazer pesquisa [...].

O telefone não para de tocar, os alunos precisam da gente e acabamos nos envolvendo com eles.

As disciplinas teórico-práticas são ainda mais cansativas temos que dar conta dos medos dos alunos, das suas inseguranças, e atender a demanda da instituição de fora.

\section{[...] é muito cansativo orientar TCC [...].}

[...] seria ótimo participar das bancas de trabalhos de conclusão de curso, se houvesse tempo para ler com calma, mas quase sempre é no afogadilho, no final dos semestres quando estamos mais apertados.

A questão da falta de tempo está presente nos depoimentos dos professores nas variadas situações e parece ser uma insígnia que marca a maioria dos docentes. Tanto quando falam de trabalho como quando se referem ao não trabalho. Assim, os relatos anteriores ilustram com clareza as angústias emergentes dos docentes, que se trabalhadas poderão repercutir em melhor qualidade de vida para os profissionais e em um desempenho favorável para os alunos.

Considerando também que a atividade de trabalho é carregada de valores e regras, mas que o ser vivente na relação com seu meio inventa e recria de acordo com suas necessidades, podemos sempre vislumbrar uma luz. O trabalho faz parte dessa atividade viva inscrita no espaço, no tempo, nos coletivos e no corpo, sendo possível a partir daí, pensar em outras formas de realização do trabalho real, já que o trabalho prescrito está ligado a uma série de normas e valores sociais. Nesse sentido, as regras de trabalho estão a todo o momento, recriadas a partir de cada trabalhador. Desenvolvendo novas normas para seu trabalho, inventando caminhos singulares que garantem e produzem saúde no trabalho ${ }^{(13)}$.

\section{CONSIDERAÇÕES FINAIS}


A participação dos professores na pesquisa ensejou, segundo relato dos entrevistados, uma reflexão sobre as relações que estabelecem entre o processo de trabalho e saúde, o que pode contribuir para a qualidade de vida nos ambientes laborais. Também, viabilizar a discussão com os diretores e coordenadores das faculdades e universidades onde realizam suas atividades sobre a atual situação dos mesmos. Ainda, encaminhar propostas que possam modificar a organização do trabalho nestas instituições e, conseqüentemente, a situação de saúde dos trabalhadores.

O professor na área da saúde, como agente de saúde, não é um simples transmissor de conhecimento, mas um agente de transformação. E suas práticas irão produzir efeitos na formação dos novos profissionais de saúde, pois a prática docente é um vetor importante nos processos de subjetivação do sujeito para formação profissional e pessoal.

A pesquisa nos oferece indícios de uma situação de precarização do trabalho docente e da produção de modos de ser professor, predominantemente, marcados pela angústia. Entretanto, é importante que se diga que o trabalho na educação não se limita às dificuldades e obediência às prescrições, mas os professores criam a todo tempo estratégias de saídas para driblar as dificuldades cotidianas e as condições deficitárias de trabalho. Mesmo com todos os obstáculos, os professores elaboram outros tipos de normas/regras que redefinem a técnica, encontrando modos de regulação que dêem conta da variabilidade inerente à sua atividade. Diante da realidade emerge o trabalho real que afirma a potência do vivo de renormatizar cotidianamente no trabalho.

Neste sentido, criar alternativas de prevenção e promoção de saúde no ambiente de trabalho, fazendo com que o trabalho seja agente ativo deste processo, é uma das nossas propostas. O próprio trabalhador docente é capaz de procurar estratégias de melhoria na qualidade de vida resgatando a função social de prazer, de solidariedade nas relações de trabalho, através das transformações externas e internas que vá buscar.

\section{REFERÊNCIAS}

1. Borges LH. Sociabilidade, sofrimento psíquico e lesões por esforços repetitivos entre caixas bancários. São Paulo: Fundacentro; 2001.

2. Gomes L. Trabalho multifacetado de professores/as: a saúde entre limites [dissertação]. Rio de Janeiro (RJ):
Ministério da Saúde Fundação Oswaldo Cruz - Fiocruz. Escola Nacional de Saúde Pública. Centro de Estudos de Saúde do Trabalhador e Ecologia Humana; 2002.

3. Tamayo MR, Tróccoli BT. Burnout no trabalho. In: Mendes AM, Borges LO, Ferreira MC, organizadores. Trabalho em transição, saúde em risco. Brasília: Universidade de Brasília; 2002.

4. Codo W. Educação: carinho e trabalho. Petrópolis: Editora Vozes; 1999.

5. Barros MEB. AEscola, as transformações dos mundos do trabalho e o trabalho docente. In: Borges LH, Moulin MGB, Araújo MD, organizadores. Organização do trabalho e saúde: múltiplas relações. Vitória: Edufes; 2001.

6. Minayo MCS. O desafio do conhecimento: pesquisa qualitativa em saúde. $4^{a}$ ed. São Paulo: Hucitec; 1996.

7. Bardin L. Análise de Conteúdo. Lisboa: Edições 70; 1995.

8. Martínez D, Valles I, Kohen J. Salud y trabajo docente: Tramas do malestar en la escuela. Buenos Aires. Argentina: Kapelusz; 1997.

9. Martins JT, Robazzi MLCC. Implementação de um currículo com mudança radical: sentimentos de prazer e sofrimento. Cogitare Enferm. 2005 Mai/Ago; 10(2):29-35.

10. Seligmann-Silva E. Psicopatologia e psicodinâmica do trabalho In: Mendes R, organizadora. Patologia do trabalho. Rio de Janeiro: Atheneu; 1995.

11. Neves MY, Viera S, Araújo A, Uchôa N. Trabalho e saúde mental: vivência subjetiva dos trabalhadores do setor da manutenção do hospital universitário/ UFPB. In: Silva Filho JF, Jardim SR, organizadores. A danação do trabalho e sofrimento psíquico: relações de trabalho e sofrimento. Rio de Janeiro. Te Cora; 1997.

12. Barros MEB. Articulações saúde-trabalho no campo de educação: os efeitos das transformações contemporâneas do trabalho docente. Projeto de pesquisa de pós-doutorado. Rio de Janeiro: Fiocruz; 2000.

13. Barros MEB, Marchiori F, Oliveira SP. Atividade de trabalho e saúde dos/as professores. Rev Trabalho, Educ Saúde. 2005 Mar; 3(1).

14. Mendes AMB, Abrahão JI. Organização do trabalho e vivências de prazer e sofrimento do trabalhador: abordagem psicodinâmica. Rev Psicol Teoria e Pesq. 1996; 12. 